\title{
Genome-wide linkage analysis for identifying quantitative trait loci involved in the regulation of lipoprotein a (Lpa) levels
}

\author{
Sonia López ${ }^{1}$, Alfonso Buil ${ }^{1,2}$, Jordi Ordoñez ${ }^{3,4}$, Juan Carlos Souto ${ }^{1}$, Laura Almasy ${ }^{5}$, \\ Mark Lathrop ${ }^{6}$, John Blangero ${ }^{5}$, Francisco Blanco-Vaca ${ }^{3,4,7}$, Jordi Fontcuberta ${ }^{1}$, \\ José Manuel Soria*,1,2
}

\footnotetext{
${ }^{1}$ Department of Hematology, Haemostasis and Thrombosis Unit, Hospital de la Santa Creu i Sant Pau, Barcelona, Spain; ${ }^{2}$ Unit of Genomic of Complex Diseases. Research Institute of Hospital de la Santa Creu i Sant Pau, Barcelona, Spain; ${ }^{3}$ Department of Biochemistry, Hospital de la Santa Creu i Sant Pau, Barcelona, Spain; ${ }^{4}$ Department of Biochemistry and Molecular Biology. Universitat Autònoma de Barcelona, Barcelona, Spain; ${ }^{5}$ Department of Population Genetics. Southwest Foundation for Biomedical Research, San Antonio, TX, USA; ${ }^{6}$ Centre National du Genotypage, Paris, France; ${ }^{7}$ CIBER de Diabetes y Enfermedades Metabólicas Asociadas
}

Lipoprotein $\operatorname{Lp}(\mathrm{a})$ levels are highly heritable and are associated with cardiovascular risk. We performed a genome-wide linkage analysis to delineate the genomic regions that influence the concentration of $\operatorname{Lp}(a)$ in families from the Genetic Analysis of Idiopathic Thrombophilia (GAIT) Project. Lp(a) levels were measured in 387 individuals belonging to 21 extended Spanish families. A total of 485 DNA microsatellite markers were genotyped to provide a $7.1 \mathrm{cM}$ genetic map. The variance component linkage method was used to evaluate linkage and to detect quantitative trait loci (QTLs). The main QTL that showed strong evidence of linkage with $\operatorname{Lp}(\mathrm{a})$ levels was located at the structural gene for apo(a) on chromosome 6 (LOD score $=13.8)$. Interestingly, another QTL influencing $L p(a)$ concentration was located on chromosome 2 with an LOD score of 2.01. This region contains several candidate genes. One of them is the tissue factor pathway inhibitor (TFPI), which has antithrombotic action and also has the ability to bind lipoproteins. However, quantitative trait association analyses performed with 12 SNPs in TFPI gene revealed no association with $\operatorname{Lp}(a)$ levels. Our study confirms previous results on the genetic basis of $\operatorname{Lp}(\mathrm{a})$ levels. In addition, we report a new QTL on chromosome 2 involved in the quantitative variation of $L p(a)$. These data should serve as the basis for further detection of candidate genes and to elucidate the relationship between the concentration of $\operatorname{Lp}(\mathrm{a})$ and cardiovascular risk.

European Journal of Human Genetics (2008) 16, 1372-1379; doi:10.1038/ejhg.2008.114; published online 18 June 2008

Keywords: lipoprotein $\mathrm{Lp}(\mathrm{a})$; quantitative trait locus (QTL); genome-wide linkage analysis; cardiovascular risk; genetic analysis of idiopathic trombophilia (GAIT)

\footnotetext{
*Correspondence: Dr JM Soria, Unit of Genomic of Complex Diseases, Research Institute of Hospital de la Santa Creu i Sant Pau, C/Sant Antoni Maria Claret, 167, Barcelona 08025, Spain.

Tel: + 349329191 93; Fax: + 349329191 92;

E-mail: jsoria@santpau.es

Received 21 December 2007; revised 16 May 2008; accepted 22 May 2008; published online 18 June 2008
}

Introduction

Lipoprotein $\mathrm{Lp}(\mathrm{a})$ is an independent risk factor for atherosclerosis and cardiovascular disease. ${ }^{1-3}$ The mechanism by which $\operatorname{Lp}(\mathrm{a})$ favours this pathological state may be related to its particular structure. It has many properties in common with low density lipoprotein (LDL), but Lp(a) 
contains apolipoprotein apo(a). Apo(a) is an hydrophilic glycoprotein structurally similar to plasminogen. It is linked to apolipoprotein B-100 by a single disulfide bond. The size of the apo(a) gene (LPA) is highly variable, resulting in different sized $L p(a)$ isoforms in the population. The size of the apo(a) isoforms is inversely correlated with $\mathrm{Lp}(\mathrm{a})$ concentration. The concentrations vary greatly among individuals and populations. In addition to the apo(a) polymorphism coding for different sized $\mathrm{Lp}(\mathrm{a})$ isoforms, an upstream pentanucleotide repeat (TTTTA(n); $n=5-12$ ) affects Lp(a) levels. Thus, the variability of the $L P A$ gene contributes to the heterogeneity of $\operatorname{Lp}(\mathrm{a})$ and influences the metabolic and physiochemical characteristics of this lipoprotein. ${ }^{4}$ In fact, the genetic variation in the LPA gene has been estimated to be responsible for $42 \%$ and even $>90 \%$ of the variation of $\mathrm{Lp}(\mathrm{a})$ concentration. ${ }^{5,6}$ According to epidemiological studies, a high concentration of $\mathrm{Lp}(\mathrm{a})$ and/or small sizes of apo(a) isoforms increase the risk of cardiovascular disease. $^{7}$

There are several hypotheses that attempt to describe the pathophysiologic mechanism of $\mathrm{Lp}(\mathrm{a})$ in atherosclerosis and cardiovascular disease. For example, oxidized phospholipids in plasma bind preferentially to $\mathrm{Lp}(\mathrm{a})$ and may contribute significantly to the increased atherogenicity of this lipoprotein. ${ }^{8}$ On the other hand, the high homology of $\mathrm{Lp}(\mathrm{a})$ to plasminogen suggests that $\mathrm{Lp}$ (a) plays a key role as a proatherothrombotic agent in atherosclerosis and cardiovascular disease due to its antifibrinolytic and procoagulant properties.

It is well known that $\operatorname{Lp}(\mathrm{a})$ levels are highly heritable. Until recently, most of the studies used genome-wide scan analyses and focused on the genetic determinants that influence $\mathrm{Lp}(\mathrm{a})$ levels. Some studies described a strong linkage at the structural gene for apo(a) on chromosome 6q26-q27. So, it is now well-established that $\mathrm{Lp}$ (a) levels are genetically determined by a variable number of kringle $(\mathrm{K})$ IV type 2 repeats in $L P A$, which lead to apo(a) isoforms of different sizes. In addition, the wide variability of $\mathrm{Lp}(\mathrm{a})$ levels may be affected also by sequence polymorphisms/ mutations in coding and noncoding regions of $L P A$. Several functionally significant single-nucleotide polymorphisms (SNPs) have been described in LPA. These polymorphisms could be responsible in part for the large quantitative variation of $\operatorname{Lp}(\mathrm{a})$ among individuals and populations. ${ }^{9-12}$ Apart from the many publications that describe association for $\mathrm{Lp}(\mathrm{a})$ located at its structural gene on chromosome 6, several recent studies have described new potential genetic determinants that may control quantitative variation of $\operatorname{Lp}(\mathrm{a}){ }^{13-15}$

The major aim of this study was to localize the quantitative trait loci (QTLs) that influence Lp(a) levels in the Spanish population. A genome-wide variance component linkage analysis of data from the GAIT Project was used to accomplish this aim.

\section{Materials and methods Subjects and phenotyping}

Our study included 387 individuals belonging to 21 Spanish families from the GAIT project. An extensive description of the GAIT project has been published previously. ${ }^{16}$ Each family was composed of 3-5 generations of individuals and the subjects ranged in age from 2 to 87 years, with a mean of 37.8 years. There were an equal number of male subjects (46\%) and female subjects (54\%) in our study. Twelve families were selected through a proband with idiopathic thrombophilia and the remaining nine families were randomly selected without regard to phenotype. Thrombophilia was defined as recurrent thrombotic episodes (at least one of which was spontaneous), a single spontaneous thrombotic event with a first-degree relative also affected, or early onset thrombosis (before the age of 45 years). The thrombophilia proband was considered idiopathic when all known biological causes of thrombophilia (ie, protein $\mathrm{S}$ and protein $\mathrm{C}$ deficiencies, antithrombin deficiency, activated protein $\mathrm{C}$ resistance and plasminogen deficiency) at the time of recruitment (since 1995-1997) were excluded.

All protocols were approved by the Institutional Review Board of the Hospital de la Santa Creu i Sant Pau (Barcelona). Adult subjects gave informed consent for themselves and for their minor children.

Blood was collected by venipuncture in $1 / 10$ volume of $0.129 \mathrm{~mol} / \mathrm{l}$ sodium citrate from fasting subjects. Thrombophilic participants were not using oral anticoagulants at the time of sampling. Platelet-poor serum samples were stored at $-80^{\circ} \mathrm{C}$ before assaying for $\mathrm{Lp}(\mathrm{a})$ levels. Serum Lp(a) levels were measured by ELISA (Apo-Tek, Organon Teknica, Turnhout, Belgium) as a part of a clinical workup, between 1995 and 1997. Normal levels of Lp(a) in serum were considered to be $<300 \mathrm{mg} / \mathrm{l}$.

\section{Genotyping}

DNA was extracted by a standard method. ${ }^{17}$. All individuals were genotyped for 485 highly informative DNA microsatellite markers, distributed through the autosomal genome at a density of $7.1 \mathrm{cM}$. The average heterozygosity of the microsatellite markers was 0.79. Microsatellites consisted primarily of the ABI Prism (Applied Biosystems, Foster City, CA) genotyping set MD-10. Linkage mapping was undertaken with the PE LMS II fluorescent marker set (ABI Prism) with multiplex PCR. ${ }^{18}$ The products from the PCR were analyzed on the PE 310, PE 377 and PE 3700 automated sequencers, and genotyped using the Genotyper software. Information on microsatellite markers can be found in the public-accessible genomic database (http:// www.gdb.org). Marker maps for multipoint analyses were obtained from the Marshfield Medical Research Organization (http://research.marshfieldclinic.org/genetics/). 
In additon, 12 SNPs (Table 3 ) in the structural TFPI gene were genotyped by using Taqman probes from Applied Biosystems (ABI Prism).

The genotypic data were entered into a database and were analyzed for discrepancies (ie, violations of Mendelian inheritance) using the program INFER (PEDSYS). ${ }^{19}$ Mistypings and markers for discrepant individuals were either corrected or excluded from the analyses.

\section{Linkage analysis}

A standard multipoint variance component linkage method was used to assess linkage between autosomal markers and levels of plasma Lp(a). This analysis was performed using the Sequential Oligogenic Linkage Analysis Routines (SOLAR) computer package. ${ }^{20}$ Previous studies suggested that such a method might be vulnerable to deviations from multivariate normality and particularly to high levels of kurtosis in the trait's distribution, giving inflated logarithm of odds (LOD) scores. ${ }^{21}$ Levels of Lp(a) in the GAIT sample exhibited a kurtosis of 0.8 after a logarithmic transformation, which does not affect the distribution of LOD scores (probability of linkage). Thus, the standard nominal $P$-values for LOD scores are appropiate for the Lp(a) linkage screen. ${ }^{22}$

Quantitative trait association analyses were performed using the measured genotyped method ${ }^{23}$ by testing for genotype-specific differences in the means of the trait while allowing for the nonindependence among family members. As 12 of the families were ascertained through thrombophilic probands, all analyses included an ascertaiment correction achieved by conditioning the likelihood of these pedigrees on the likelihoods of their respective probands. ${ }^{24}$ To control the multiple testing effect, genomewide $P$-values were calculated using the method of Feingold et al. ${ }^{25}$

\section{Results}

The pedigree data extracted from the GAIT database consisted of 21 families with 387 individuals providing data for $\mathrm{Lp}$ (a) levels and for the covariates used in the analysis, such as gender, age, total cholesterol, smoking behavior, use of oral contraceptives and the household effect. Table 1 summarizes the phenotypic characteristics of the individuals in our study.

Total cholesterol levels and smoking behavior were the only covariates that showed a significant effect over Lp(a) levels $(P=0.0042$ and $P=0.019$, respectively). Neither the gender nor age effects were significant. No significant household effect was found in our samples. The range of Lp(a) levels in the GAIT sample was $0.21-242.30 \mathrm{mg} / \mathrm{l}$, with a mean of $33.38 \mathrm{mg} / \mathrm{l}$.

The overall genetic heritability $\left(\mathrm{h}^{2}\right)$ of the concentration of $\operatorname{Lp}(\mathrm{a})$ was estimated to be $0.79 \pm 0.07$, indicating that
Table 1 Phenotypic characteristics of the 387 individuals included in the study

\begin{tabular}{lc}
\hline Characteristics & Frequency (\%) or Mean $\pm S D$ \\
\hline No. of families & 21 \\
No. of individuals & 387 \\
Sex & \\
$\quad$ Male & $178(46 \%)$ \\
Female & $209(54 \%)$ \\
Age (years) & $37.8 \pm 19.81$ \\
Smokers & \\
Total cholesterol (mmol/l) & $146(38 \%)$ \\
Lp(a) (mg/l) & $5.19 \pm 1.15$ \\
\hline
\end{tabular}

${ }^{a}$ Individuals in the study were defined as smokers when they usually smoke, independently of the number of cigarettes.

$79 \%$ of the phenotypic variation in this trait is due to the additive effect of genes.

A standard multipoint variance component method was used to assess linkage between autosomal DNA markers, spaced at $\sim 7.1 \mathrm{cM}$, and quantitative values of $\operatorname{Lp}(\mathrm{a})$. The proportion of the $\operatorname{Lp}(\mathrm{a})$ variance due to the covariates used in the analysis was estimated as 5\%. Their effects were estimated simultaneously with the genetic effects.

The results from the linkage analysis revealed strong evidence for a quantitative trait locus (QTL) on the long arm of chromosome 6 (6q), which may influence $L p(a)$ levels $(\mathrm{LOD}=13.8$; nominal $P=7.77 \mathrm{e}-16$ and genomewide $P=2.54 \mathrm{e}-13$ ) (Figure 1 ). The QTL on chromosome 6 was detected through a peak LOD score located in the interval flanked by markers D6S441 and D6S264 in a region that maps to $6 \mathrm{q} 25.2-6 \mathrm{q} 27$. Specific data from the linkage analysis can be found in Table 2 . This region contains the structural gene of apo(a). Another linkage signal was detected on the long arm of chromosome 17 (17q) with a genome-wide $P$-value of 0.0179 , indicating a potential additional genomic region that may be involved in the control of the concentration of $\operatorname{Lp}(\mathrm{a})$.

To look for additional genomic regions controlling $\mathrm{Lp}(\mathrm{a})$ levels, we carried out a multilocus linkage analysis, which took into account the effect of the QTL on chromosome 6, by fixing this position in the model and rescanning the genome (Figure 2 and Table 2). In the second linkage pass, which was conditioned on chromosome 6 QTL detected in the initial screen, evidence of linkage on chromosome 17 disappeared $(\mathrm{LOD}=0.7)$ indicating that the initial signal was a false positive. It is important to note that we were able to detect a new genomic region on the long arm of chromosome $2(2 \mathrm{q})$ with suggestive linkage $(\mathrm{LOD}=2.01$; $P=0.0011$ ). The new QTL on chromosome 2 was located between markers D2S335 and D2S2289, at chromosome position $206 \mathrm{cM}$, in a region that maps to $2 \mathrm{q} 31.1-2 \mathrm{q} 33.2$ (Figure 3 and Table 2). A bioinformatic search in this region showed several potential candidate genes. One of them was the tissue factor pathway inhibitor (TFPI: Ensembl Gene ID: 


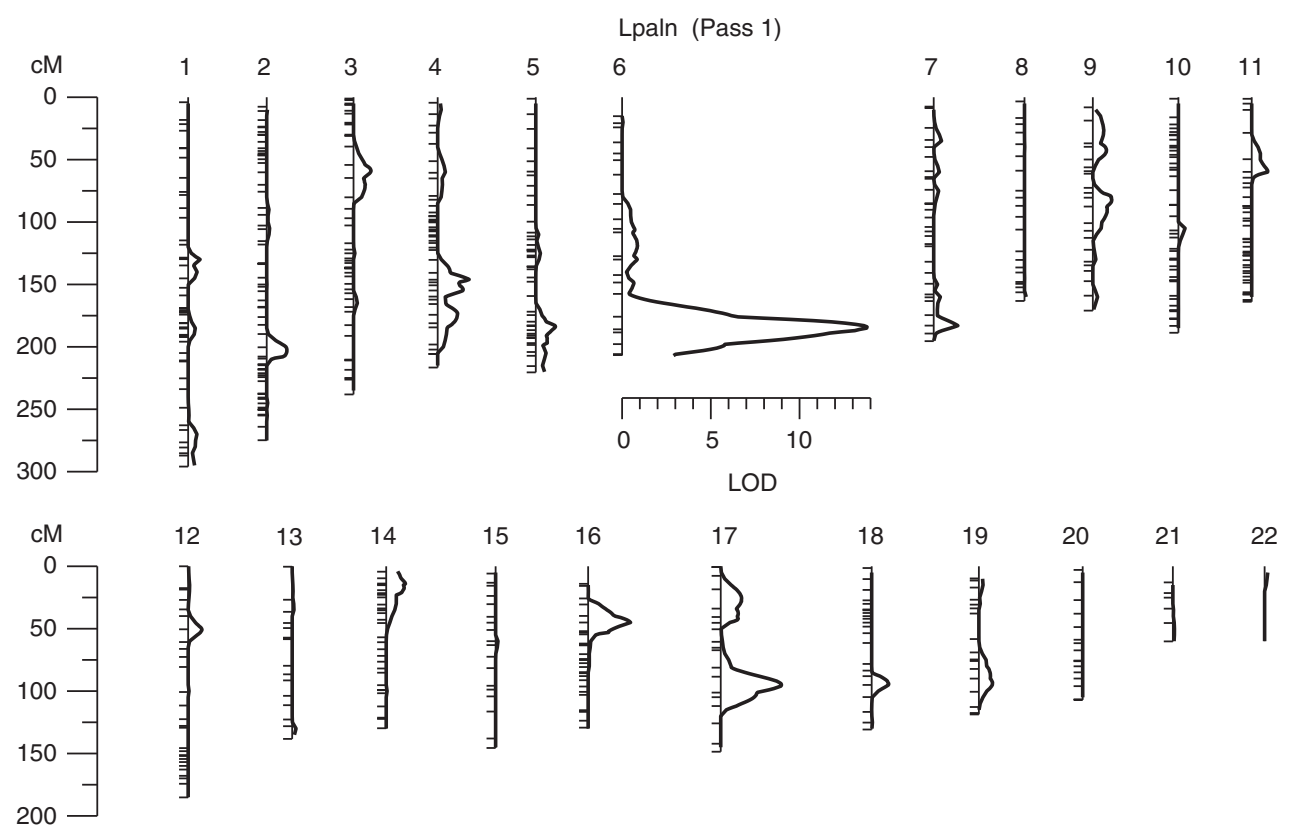

Figure 1 Results of the linkage screen for lipoprotein $\operatorname{Lp}(\mathrm{a})$. There is a major linkage signal on chromosome $6(\operatorname{LOD}=13.8)$. Significant linkage response was detected also on chromosome $17(\mathrm{LOD}=3.4)$.

Table 2 Results of the sequential oligogenic linkage analysis of variation in Lp(a) levels

\begin{tabular}{|c|c|c|c|c|c|c|c|c|}
\hline \multirow[b]{2}{*}{ Chromosome } & \multirow[b]{2}{*}{ Flanking markers } & \multirow[b]{2}{*}{$\begin{array}{l}\text { Chromosome. } \\
\text { position (cM) }\end{array}$} & \multicolumn{3}{|c|}{ First pass } & \multicolumn{3}{|c|}{ Second pass } \\
\hline & & & LOD score & $\begin{array}{l}\text { Nominal } \\
\text { P-value }\end{array}$ & $\begin{array}{c}\text { Genome-wide } \\
\text { P-value }\end{array}$ & LOD score & $\begin{array}{l}\text { Nominal } \\
\text { P-value }\end{array}$ & $\begin{array}{c}\text { Genome-wide } \\
\text { P-value }\end{array}$ \\
\hline 6 & D6S441-D6S264 & 184 & 13.8 & $7.77 e-16$ & $2.54 \mathrm{e}-13$ & - & & \\
\hline 17 & D17S787-D17S944 & 95 & 3.4 & $3.61 e-05$ & 0.01791 & 0.7 & 0.0363 & NS \\
\hline 2 & D2S335-D2S2289 & 206 & - & & & 2.01 & 0.0011 & 0.5394 \\
\hline
\end{tabular}

NS, not significant.

ENSG00000003436). This gene encodes a protein that has an antithrombotic action and also the ability to associate with lipoproteins in plasma. Encouraged by this result, we genotyped 12 SNPs in the TFPI gene (Table 3) including three reported as functional (rs5940; rs10153820 and P151L), and looked for the association with $\mathrm{Lp}$ (a) levels. However, the measured genotype analysis revealed no significant association of any of these polymorphisms and the Lp(a) levels (Table 3). In addition, 23 haplotypes were analyzed using all these SNPs; however no significant association with $\operatorname{Lp}(\mathrm{a})$ levels was found (data not shown).

\section{Discussion}

Lipoprotein $\mathrm{Lp}(\mathrm{a})$ is a low-density lipoprotein particle linked to apolipoprotein apo(a). It is one of the wellestablished risk factors for atherosclerosis and cardiovascular disease. The understanding of the physiologic mechanisms and genetic determinants of $\mathrm{Lp}(\mathrm{a})$ should help to elucidate the contribution of this quantitative trait to the risk of cardiovascular disease. Accordingly, the concentration of $\mathrm{Lp}(\mathrm{a})$ is highly heritable and a large number of studies have attempted to identify the genomic regions that influence $\mathrm{Lp}(\mathrm{a})$ levels. Specifically, heritability $\left(\mathrm{h}^{2}\right)$ for $\mathrm{Lp}(\mathrm{a})$ was estimated in several studies and ranged from 0.69 to $0.944^{13-15,26-28}$ In agreement with these results, we estimated the $\mathrm{h}^{2}$ of $\mathrm{Lp}(\mathrm{a})$ in the Spanish population in 0.79 . This means that $79 \%$ of the variance of $\mathrm{Lp}(\mathrm{a})$ is attributable to genetic factors. Given the high heritability for $\mathrm{Lp}(\mathrm{a})$ obtained in our GAIT sample, we conducted a genome-wide scan analysis to identify the genomic regions that influence the $\mathrm{Lp}(\mathrm{a})$ concentration.

We detected a strong linkage signal at the LPA gene on Chromosome 6q25.2-q27 with a LOD score of 13.8. This result agrees with the results from previous studies that investigated the $\operatorname{Lp}(\mathrm{a})$ trait and found a highly significant linkage at the structural LPA gene on chromosome $6 .^{6,13-15,28,29}$ On the other hand, it is noteworthy 

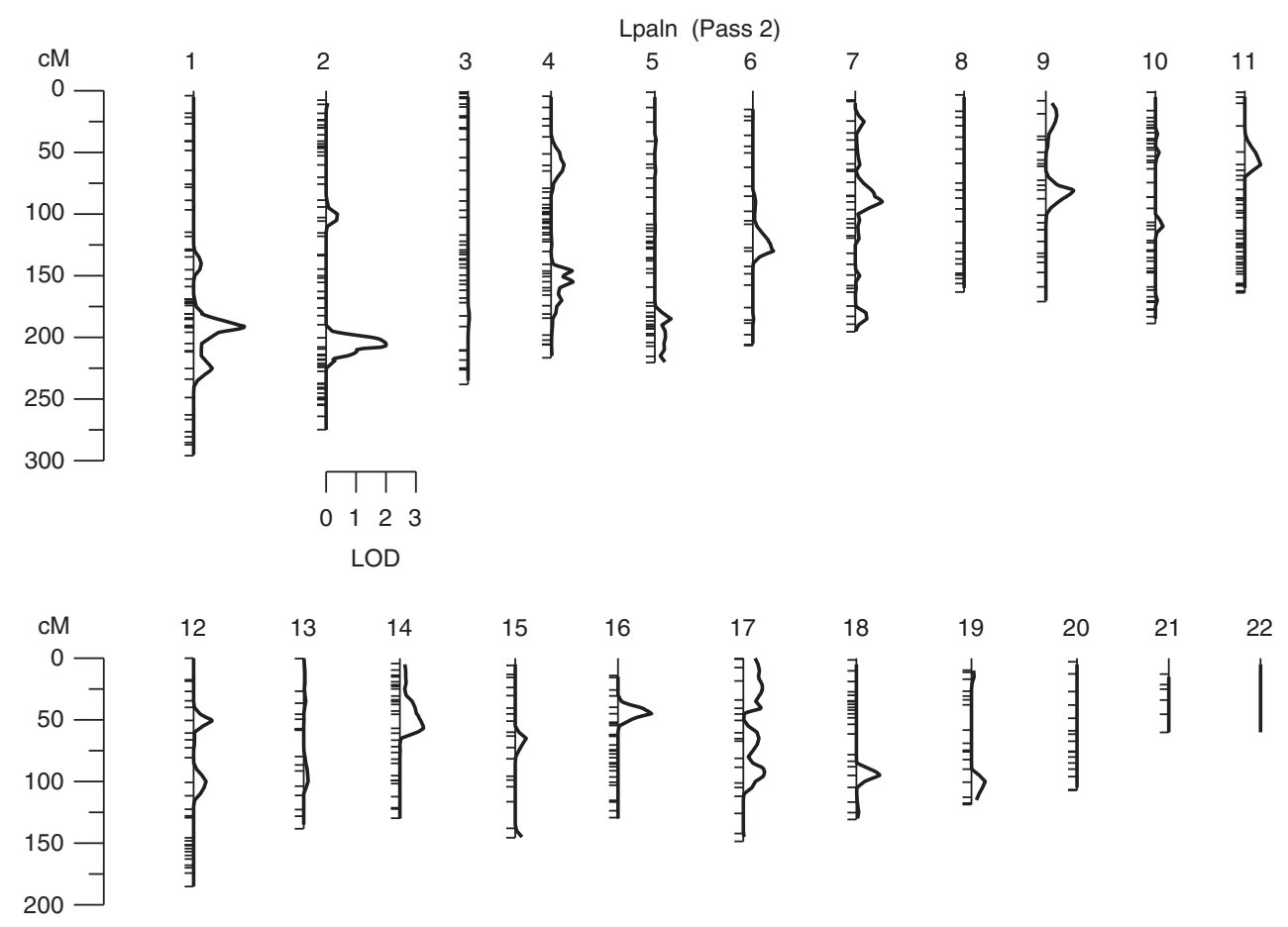

Figure 2 Results of the second linkage pass conditioned on chromosome 6 QTL.

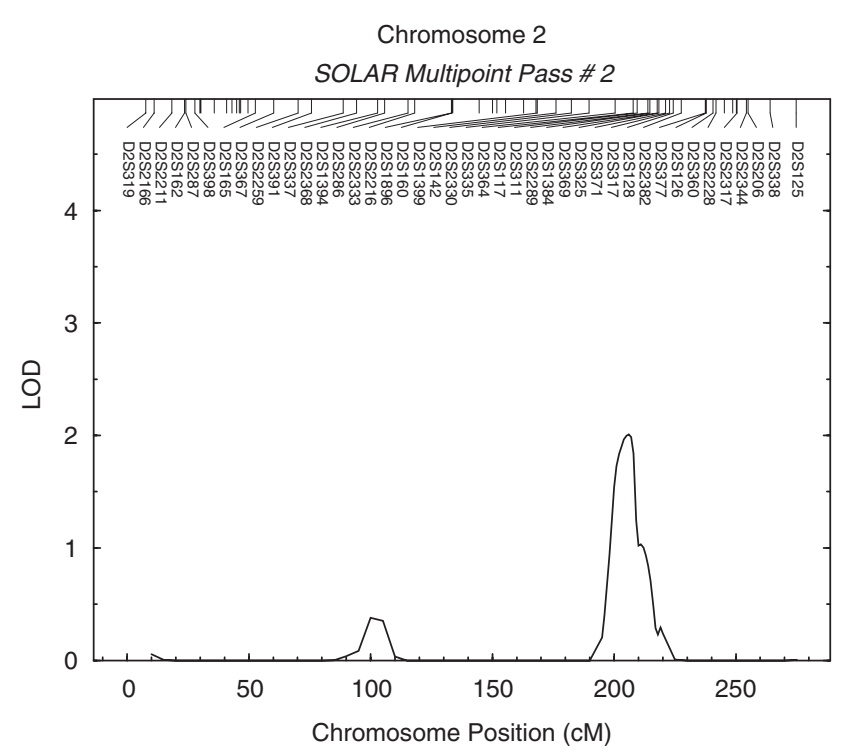

Figure 3 Detailed linkage results for chromosome 2. Significant linkage signal was detected by a peak LOD score of 2.01 (nominal $P=0.0011$ and genome-wide $P=0.5394$ ) defining a quantitative trait locus for Lp(a) between markers D2S335 and D2S2289 at chromosome position $206 \mathrm{cM}$ in a region that maps to $2 q 31.1-2 q 33.2$.

that when we conditioned the linkage analysis to the strong signal on chromosome 6 (where the structural LPA gene maps), a new QTL involved in the control of $\mathrm{Lp}(\mathrm{a})$ levels became evident. This QTL is located in a region that maps to chromosome 2q31.1-2q33.2. According to our results, the genomic regions that influence $\mathrm{Lp}(\mathrm{a})$ concentration are not limited to the structural $L P A$ gene on chromosome 6. Accordingly, several recent genome-wide scans have described other new potential genetic determinants that may control quantitative variation of $\mathrm{Lp}(\mathrm{a})$. However, any of them showed a significant signal on chromosome 2 . This may be possible due to the fact that the genetic factors contributing to a complex trait may differ among populations. In agreement with this argument, it is possible that the new QTL on chromosome 2 may play a functional role on $\mathrm{Lp}$ (a) levels only in the Spanish population. In addition, given that the major genetic factor that influence $\mathrm{Lp}$ (a) levels accounts for $>90 \%$ of variance, other genes that have a small effect on this trait must be hard to find. Another reason for such differences in reporting QTLs between different studies might be that there is insufficient statistical power because of the study design or the sample size or the small effect of these QTLs. Finally, exists the possibility that these other gene(s) involved in affecting small quantitative variation of $\mathrm{Lp}(\mathrm{a})$ in different populations may actually respond to different biological causes that could indeed may be controlling the participation of these genes in the control of $\operatorname{Lp}(\mathrm{a})$ levels. A review of these results is summarized in Table 4.

This genomic region influencing $\mathrm{Lp}(\mathrm{a})$ on chromosome $2 \mathrm{q}$ contains several genes that could be candidate genes involved in the control of $\operatorname{Lp}(\mathrm{a})$ levels. One of them is the 
Table 3 List of SNPs genotyped in the TFPI gene

\begin{tabular}{|c|c|c|c|c|c|}
\hline SNP & Chromosome 2 position (bp) & $\mathrm{P}$-value $e^{\mathrm{a}}$ & $M A F^{b}$ & beta ${ }^{c}$ & $E_{b e t a}{ }^{\mathrm{d}}$ \\
\hline rs5940 & 188039949 & 0.873 & 0.015 & -0.010 & -1.010 \\
\hline rs10153820 & 188127835 & 0.784 & 0.124 & -0.086 & -1.090 \\
\hline P151 L & 188057188 & 0.616 & 0.004 & 0.388 & 1.474 \\
\hline rs 2268300 & 188042980 & 0.714 & 0.008 & -0.108 & -1.114 \\
\hline rs6736363 & 188067265 & 0.124 & 0.031 & 0.521 & 1.684 \\
\hline rs 2300412 & 188076120 & 0.544 & 0.392 & 0.044 & 1.045 \\
\hline rs3755248 & 188078477 & 0.506 & 0.316 & 0.036 & 1.037 \\
\hline rs4667168 & 188101185 & 0.639 & 0.107 & -0.065 & -1.067 \\
\hline rs35935664 & 188104581 & 0.768 & 0.259 & -0.051 & -1.052 \\
\hline rs13427829 & 188112528 & 0.611 & 0.103 & -0.080 & -1.084 \\
\hline rs7594359 & 188117093 & 0.952 & 0.448 & 0.021 & 1.021 \\
\hline rs6434222 & 188120489 & 0.621 & 0.133 & -0.089 & -1.093 \\
\hline
\end{tabular}

${ }^{a} P$-value of association with $\mathrm{Lp}(\mathrm{a})$ levels.

${ }^{b}$ Minimal allele frequency of the SNP in our sample.

${ }^{c}$ Represents the effect of one copy of the rare allele in $L p(a)$ levels when it is expressed in logarithmic scale.

${ }^{d}$ Represents the effect of one copy of the rare allele in $L p(a)$ levels when it is expressed in original scale.

Table 4 Genomic regions that influence $L p(a)$ levels reported in recent studies as of this date

\begin{tabular}{|c|c|c|c|c|c|}
\hline Author & Chromosome & LOD score & Flanking markers & $\begin{array}{l}\text { Chromosome } \\
\text { position (cM) }\end{array}$ & Population studied \\
\hline \multirow[t]{2}{*}{ Barlera et al ${ }^{13}$} & 6 & 108.3 & D6S1581-D6S1599 & 189 & \multirow[t]{2}{*}{$\begin{array}{l}1812 \text { families, including } 4012 \\
\text { individuals, from the PROCARDIS } \\
\text { coronary artery disease (CAD) } \\
\text { study, in which } 80 \% \text { of individuals } \\
\text { analyzed were affected by CAD. }\end{array}$} \\
\hline & $\begin{array}{r}13 \\
11 \\
15 \\
19 \\
1\end{array}$ & $\begin{array}{l}7.0 \\
3.5 \\
2.9 \\
2.7 \\
1.5\end{array}$ & $\begin{array}{l}\text { D13S156-D13S265 } \\
\text { D11S902-D11S904 } \\
\text { D15S131-D15S205 } \\
\text { D19S571-D19S418 } \\
\text { D1S498-D1S484 }\end{array}$ & $\begin{array}{r}85 \\
35 \\
76 \\
97 \\
-\end{array}$ & \\
\hline \multirow[t]{5}{*}{ Barkley et $a l^{15}$} & 6 & 18.62 & - & 160 & \multirow{5}{*}{$\begin{array}{l}1046 \text { Nonhispanic white } \\
\text { individuals }{ }^{\mathrm{b}} \text {. } \\
1556 \text { African American } \\
\text { individuals } \mathrm{s}^{\mathrm{b}} \text {. } \\
1061 \text { hispanic white individuals }^{\mathrm{b}} \text {. } \\
1046 \text { nonhispanic white } \\
\text { individuals }{ }^{\mathrm{b}} \text {. } \\
1061 \text { hispanic white individuals }^{\mathrm{b}} \text {. } \\
1046 \text { nonhispanic white } \\
\text { individuals }{ }^{\mathrm{b}} \text {. }\end{array}$} \\
\hline & & 14.27 & - & 164 & \\
\hline & & 12.97 & - & 163 & \\
\hline & 12 & 1.60 & - & 38 & \\
\hline & $\begin{array}{l}14 \\
19\end{array}$ & $\begin{array}{c}2.56 \\
3.8 / 2.52\end{array}$ & - & $\begin{array}{r}17 \\
30 / 47\end{array}$ & \\
\hline \multirow[t]{2}{*}{ Beekman et al 29} & 6 & $9.8 \rightarrow 8.2^{\mathrm{a}}$ & - & 163 & \multirow[t]{2}{*}{$\begin{array}{l}483 \text { dizygotic and } 967 \\
\text { monozygotic twin pairs recruited } \\
\text { regardless of their health status. }\end{array}$} \\
\hline & $1 \rightarrow-^{a}$ & $1.6 \rightarrow 0^{\mathrm{a}}$ & - & 251 & \\
\hline \multirow[t]{2}{*}{ Broeckel et al ${ }^{14}$} & 6 & 26.99 & D6S305 & 166 & \multirow[t]{2}{*}{$\begin{array}{l}513 \text { western European families, } \\
\text { including } 1406 \text { individuals, with at } \\
\text { least two members affected of early } \\
\text { onset myocardial infarction and/or } \\
\text { severe premature CAD. }\end{array}$} \\
\hline & 1 & 3.81 & D1S1679 & 170 & \\
\hline
\end{tabular}

${ }^{a}$ In the study of Beekman et al, ${ }^{29}$ evidence for linkage on chromosome 1 completely disappeared $(\mathrm{LOD}=0)$ when further analysis in a two locus model was performed, whereas the strong linkage signal for chromosome 6 remained unaltered.

${ }^{b}$ All the individuals were recruited from the Genetic Epidemiology Network of Arteriopathy study of the Family Blood Pressure Program. Further genetic linkage evidence has been found on chromosomes 12 and 19 in nonhispanic whites, as well as on chromosome 14 in hispanic whites. However, there has been a lack of linkage response on these chromosomes in African Americans. 
TFPI. This gene encodes a protein that inhibits factor $\mathrm{X}$ activated (X(a)) directly and, in a Xa-dependent way, inhibits VIIa/tissue-factor activity, presumably by forming a quaternary $\mathrm{Xa} / \mathrm{LACI} / \mathrm{VIIa} / \mathrm{TF}$ complex. It has antithrombotic action and also the ability to associate with lipoproteins. Accordingly, a recent study ${ }^{30}$ shows that Lp(a) binds and inhibits TFPI in vitro. This biologic interaction promotes the prothrombotic action of $\mathrm{Lp}(\mathrm{a})$ mediated through the inhibition of the anticoagulant activity of TFPI and suggest a new important link between lipoproteins and thrombosis. With these studies as background, we performed quantitative trait association analyses with an extensive set of SNPs in the TFPI gene and Lp(a) concentration. Although, the lack of association of these SNPs and Lp(a) levels does not rule out the possibility that other polymorphisms in the TFPI gene could be associated with $\operatorname{Lp}(\mathrm{a})$, the most plausible hypothesis is that another gene in this region different from TFPI is responsible of the linkage signal.

Interestingly, the genomic region between markers defining the QTL located on chromosome 2 also includes four additional genes that need to be considered. These genes are OSBPL6 (oxysterol-binding protein-related protein 6); NDUFB3 (mitochondrial NADH dehydrogenase 1 beta subcomplex subunit 3), COQ10 B (mitochondrial precursor protein coenzyme Q10 homolog B) and AOX1 (aldehyde oxidase).

The OSBPL6 gene encodes a protein involved in the transport of lipids, in the regulation of cholesterol homeostasis and in signal transduction pathways of lipid metabolism. ${ }^{31}$ We believe that the OSBPL6 protein might be involved in the regulation of $\mathrm{Lp}(\mathrm{a})$ levels by an unknown mechanism, probably related with the action of oxysterols as potential signaling molecules, which accumulate in the atherosclerotic lesions in arterial walls.

In addition, both the NDUFB3 and the CoQ10 B genes encode proteins of the mitochondrial respiratory chain. These proteins are part of two important sites of free radicals generated in mitochondria. These free radicals increase the oxidative stress and cellular damage. ${ }^{32}$ Furthermore, the enzyme aldehyde oxidase, which belongs to the xanthine dehydrogenase family, also causes an increase in oxidative cell damage by producing hydrogen peroxide and, under certain conditions, catalyzes the formation of superoxide. ${ }^{33}$ It is widely known that oxidative stress plays a key role in the development of cardiovascular disease and atherosclerosis. Moreover, oxidized phospholipids in plasma circulate, preferentially, on $\operatorname{Lp}(\mathrm{a})$ and may contribute significantly to the increased atherogenicity of this lipoprotein. ${ }^{8}$

In this complex scenario, with several potential candidate genes, which may explain the genetic variability of Lp(a) levels, further analyses are needed that focus on fine mapping. With these new data, the mechanism by which the locus on chromosome 2 modulates Lp(a) levels may become clear. Our results provide a framework for these additional studies.

Finally, despite the fact that other genes different from LPA gene would probably have a small effect on $\operatorname{Lp}(\mathrm{a})$ levels, it is prudent to think in terms of networks of genes and systems when considering control of this trait rather than of individual genes.

\section{Acknowledgements}

We acknowledge the advice and helpful discussion of Professor WH Stone. This study was supported partially by Grants no. 2 RO1 HL070751-05 from the USA NIH, PI-05/1361, PI-05/1382 and Redes Temáticas de Investigación Cooperativa (RETIC) Cardiovascular (RECAVA: Exp-06/0014/0016RD Ministerio de Sanidad y Consumo, Spain), SAF2005-04738 from Ministerio de Ciencia y Tecnología and FEDER (Spain), SGR 01068 from Agència de Gestió d'ajuts Universitaris $i$ de Recerca and 'Red FIS de Diabetes y Enfermedades Metabólicas Asociadas RD06/0015'. JM Soria was supported by 'Programa d'Estabilització d'Investigador de la Direcció d'Estrategia $i$ Coordinació del Departament de Salut' (Generalitat de Catalunya). Finally, we are indebted to all of the families who participated in the GAIT project.

\section{References}

1 Marcovina SM, Koschinsky ML: Lipoprotein(a) as a risk factor for coronary artery disease. Am J Cardiol 1998; 82: 57U-66U.

2 Danesh J, Collins R, Peto R: Lipoprotein(a) and coronary heart disease. Meta-analysis of prospective studies. Circulation 2000; 102: $1082-1085$.

3 Koschinsky ML: Novel insights into Lp(a) physiology and pathogenicity: more questions than answers? Cardiovasc Hematol Disord Drug Targets 2006; 6: 267-278.

4 Berglund L, Ramakrishnan R: Lipoprotein(a): an elusive cardiovascular risk factor. Arterioscler Thromb Vasc Biol 2004; 24: 2219-2226.

5 Boerwinkle E, Menzel HJ, Kraft HG, Utermann G: Genetics of the quantitative $\mathrm{Lp}(\mathrm{a})$ lipoprotein trait. III. Contribution of $\mathrm{Lp}(\mathrm{a})$ glycoprotein phenotypes to normal lipid variation. Hum Genet 1989; 82: 73-78.

6 Boerwinkle E, Leffert CC, Lin J, Lackner C, Chiesa G, Hobbs HH: Apolipoprotein(a) gene accounts for greater than $90 \%$ of the variation in plasma lipoprotein(a) concentrations. J Clin Invest 1992; 90: 52-60.

7 Paultre F, Pearson TA, Weil HF et al: High levels of Lp(a) with a small apo(a) isoform are associated with coronary artery disease in African American and white men. Arterioscler Thromb Vasc Biol 2000; 20: 2619-2624.

8 Tsimikas S, Tsironis LD, Tselepis AD: New insights into the role of lipoprotein(a)-associated lipoprotein-associated phospholipase A2 in atherosclerosis and cardiovascular disease. Arterioscler Thromb Vasc Biol 2007 and N Engl J Med 2005; 353: 46-57.

9 Luke MM, Kane JP, Liu DM et al: A polymorphism in the proteaselike domain of apolipoprotein(a) is associated with severe coronary artery disease. Arterioscler Thromb Vasc Biol 2007; 27: 2030-2036.

10 Chretien JP, Coresh J, Berthier-Schaad Y et al: Three singlenucleotide polymorphisms in LPA account for most of the increase in lipoprotein(a) level elevation in African Americans compared with European Americans. J Med Genet 2006; 43: 917-923.

11 Ogorelkova M, Kraft HG, Ehnholm C, Utermann G: Single nucleotide polymorphisms in exons of the apo(a) kringles IV types 6-10 domain affect $\operatorname{Lp}(\mathrm{a})$ plasma concentrations and have 
different patterns in Africans and Caucasians. Hum Mol Genet 2001; 10: 815-824.

12 Parson W, Kraft HG, Niederstatter $\mathrm{H}$ et al: A common nonsense mutation in the repetitive Kringle IV-2 domain of human apolipoprotein(a) results in a truncated protein and low plasma Lp(a). Hum Mutat 2004; 24: 474-480.

13 Barlera S, Specchia C, Farrall M et al: Multiple QTL influence the serum $\mathrm{Lp}(\mathrm{a})$ concentration: a genome-wide linkage screen in the PROCARDIS study. Eur I Hum Genet 2007; 15: 221-227.

14 Broeckel U, Hengstenberg C, Mayer B et al: A comprehensive linkage analysis for myocardial infarction and its related risk factors. Nat Genet 2002; 30: 210-214.

15 Barkley RA, Brown AC, Hanis CL, Kardia SL, Turner ST, Boerwinkle E: Lack of genetic linkage evidence for a trans-acting factor having a large effect on plasma lipoprotein[a] levels in African Americans. J Lipid Res 2003; 44: 1301-1305.

16 Souto JC, Almasy L, Borrell M et al: Genetic determinants of hemostasis phenotypes in Spanish families. Circulation 2000; 101: $1546-1551$.

17 Miller SA, Dykes DD, Polesky HF: A simple salting out procedure for extracting DNA from human nucleated cells. Nucleic Acids Res 1988; 16: 1215.

18 Soria JM, Almasy L, Souto JC et al: A quantitative-trait locus in the human factor XII gene influences both plasma factor XII levels and susceptibility to thrombotic disease. Am J Hum Genet 2002; 70: $567-574$.

19 Dyke B: PEDSYS: a pedigree data management sytem. User's manual. Tech. Rep. No. 2 San Antonio, Texas: Southwest Foundation for Biomedical Research, 1995.

20 Almasy L, Blangero J: Multipoint quantitative-trait linkage analysis in general pedigrees. Am J Hum Genet 1998; 62: 1198-1211.

21 Allison DB, Neale MC, Zannolli R, Schork NJ, Amos CI, Blangero $\mathrm{J}$ : Testing the robustness of the likelihood-ratio test in a variancecomponent quantitative-trait loci-mapping procedure. Am J Hum Genet 1999; 65: 531-544.

22 Blangero J, Williams JT, Almasy L: Robust LOD scores for variance component-based linkage analysis. Genet Epidemiol 2000; 19: S8-14.
23 Hopper JL, Mathews JD: Extensions to multivariate normal models for pedigree analysis. Ann Hum Genet 1982; 46: $373-383$.

24 Boehnke M, Lange K: Ascertainment and goodness of fit of variance component models for pedigree data. Prog Clin Biol Res 1984; 147: 173-192.

25 Feingold E, Brown PO, Siegmund D: Gaussian models for genetic linkage analysis using complete high-resolution maps of identity by descent. Am J Hum Genet 1993; 53: 234-251.

26 Mitchell BD, Kammerer CM, Blangero J et al: Genetic and environmental contributions to cardiovascular risk factors in Mexican Americans. The San Antonio Family Heart Study. Circulation 1996; 94: 2159-2170.

27 Ober C, Abney M, McPeek MS: The genetic dissection of complex traits in a founder population. Am J Hum Genet 2001; 69: $1068-1079$.

28 Austin MA, Sandholzer C, Selby JV, Newman B, Krauss RM, Utermann G: Lipoprotein(a) in women twins: heritability and relationship to apolipoprotein(a) phenotypes. Am J Hum Genet 1992; 51: 829-840.

29 Beekman M, Heijmans BT, Martin NG et al: Two-locus linkage analysis applied to putative quantitative trait loci for lipoprotein(a) levels. Twin Res 2003; 6: 322-324.

30 Caplice NM, Panetta C, Peterson TE et al: Lipoprotein (a) binds and inactivates tissue factor pathway inhibitor: a novel link between lipoproteins and thrombosis. Blood 2001; 98: 2980-2987.

31 Olkkonen VM, Lehto M: Oxysterols and oxysterol binding proteins: role in lipid metabolism and atherosclerosis. Ann Med 2004; 36: 562-572.

32 Adam-Vizi V, Chinopoulos C: Bioenergetics and the formation of mitochondrial reactive oxygen species. Trends Pharmacol Sci 2006; 27: 639-645.

33 Kundu TK, Hille R, Velayutham M, Zweier JL: Characterization of superoxide production from aldehyde oxidase: an important source of oxidants in biological tissues. Arch Biochem Biophys 2007; 460: 113-121. 